\title{
Aberrant Confluence of Intrahepatic Biliary Ducts - A Case Report
}

\author{
Dragica Jurkovikj ${ }^{*}$, Kostadina Korneti-Pekevska \\ Institute of Anatomy, Medical Faculty, Ss Cyril and Methodius University of Skopje, Skopje, Republic of Macedonia
}

\begin{abstract}
Citation: Jurkovikj D, Korneti-Pekevska K. Aberrant Confluence of Intrahepatic Biliary Ducts - A Case Report. Maced J Med Sci. 2013 Mar 15; 6(1):69-73. http://dx.doi.org/10.3889/MJMS.1857-5773.2013.0275. Key words: biliary ducts; aberrant inflow; anatomy; topography; portal vein

"Correspondence: Dragica Jurkovikj, MD. Institute of Anatomy, Medical Faculty, Ss Cyril and Methodius University of Skopje, Skopje, Republic of Macedonia E-mail: dragica.jurkovik@gmail.com

Received: 01-Nov-2012; Revised: 24-Jan-2013; Accepted: 24-Jan-2013; Online first: 23-Feb-2013 Copyright: (c) 2013 Jurkovikj D. This is an openaccess article distributed under the terms of the Creative Commons Attibution License, which preative Commons Attibution License, which permits un in any medium, provided the original reproduction in any medium, provided the author and source are credited.

Competing Interests: The author have declared that no competing interests exist.
\end{abstract}

\begin{abstract}
Aim: Besides the most frequent-modal type of confluent patterns intrahepatic biliary ducts, there are cases with aberrant type of confluence. The aim of this report is to present a case with aberrant confluence of intrahepatic biliary ducts.

Material and Methods: Injection-corrosive method was used to obtain acrylic cast from biliary and portal systems of one human liver. Biliary ducts were followed parallel to the adjoint portal ramification from the initial part of segmental ductules.

Results: Nine portal segments of the liver were established. Segmental biliary ducts and their confluence subsequently from IV to I order, were also seen. The right hepatic duct was absent. The posterior and anterior right sectorial ducts joined consecutively the opposite left hepatic duct in front of the portal bifurcation. As to the segmental ducts $2^{\text {nd }}$ segment duct inflow the left hepatic duct, then $3^{\text {rd }}$ segment duct had merging pattern of double medial sector duct as well as three segmental ducts $5^{\text {th }}, 6^{\text {th }}$ and $7^{\text {th }}$ had inflow pattern in posterior sector duct. This specimen with aberrant confluence of intrahepatic ducts has been selected to point out the "close" relationship of found aberrant bile ducts in the liver region.
\end{abstract}

Conclusion: The knowledge of the aberrant anatomy of biliary ducts emphasizes the importance in clinical practice of basic information for portobiliary topography.

\section{Introduction}

The aberrant biliary anatomy is a congenital liver disorder which may be discover. In this context we could find out the previously investigated and classified confluence patterns of the biliary system according to Claude Couinaud [1-2] and as classified by Huang [3].

We had comprehended this specimen as a casual having in mind his practical implication.

The aim of this report is to present a case with aberrant confluence of intrahepatic biliary ducts.

\section{Material and Methods}

One selected specimen of adult human liver obtained post mortem was presented. Injectioncorrosive method was used to obtain acrylic cast from biliary and portal systems of the liver. After dissection of the perihilar connective tissue into the extrahepatic part of the bile ducts colored yellow acrylate and uncolored redish one into the portal vein, were injected. The injected porto-biliary elements were ligated and after polimerisation of the acrylate, a corrosion was made in the concentrated $\mathrm{HCl}$ acid.

On the obtained cast biliary ducts were followed parallel to the adjoint portal ramification from the initial part of segmental ductules. A schematic drawing for the biliary and portal elements, as well as portal segmentation was made.

In accordance with established functional anatomy i.e. subdivision of presented specimen, a confluence pattern of intrahepatic bile ducts and upper biliary confluence, in relation to the portal ramification were described. At the same time, an aberrant confluence of sectorial and segmental ducts was followed. 


\section{Results}

Nine portal segments of the liver were discovered on the basis of the portal branching in the examined cast (Figures 1 and 2).

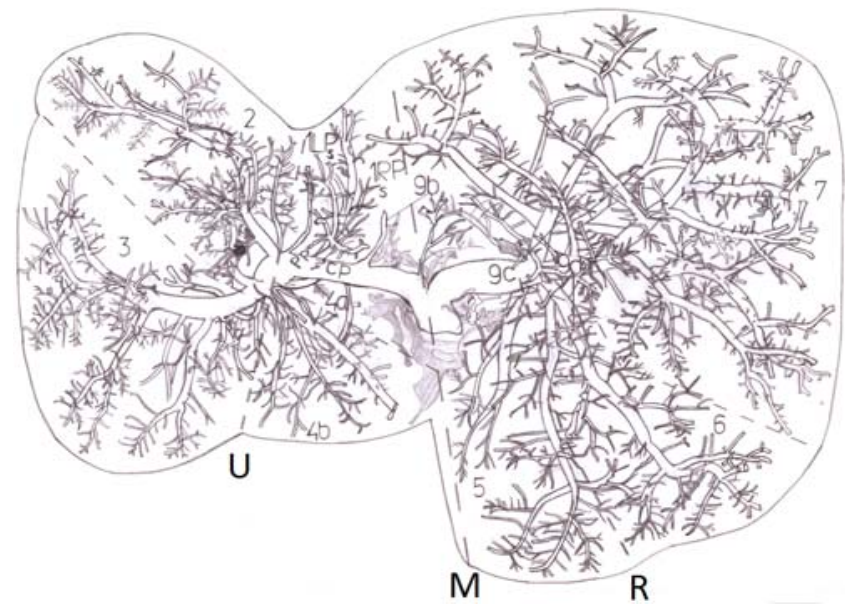

Figure 1: Intrahepatic branching of the portal vein. Portal segmentation outlining on the visceral surface. The planes of the first to the third order division are marked: Main portal plane (midplane)-M, Right portal intersectorial plane-R, Left portal intersectorial plane (umbilical)- $U$ and intersegmental planes.

Also, segmental biliary ducts and their confluence, subsequently from IV to I order, were seen (Figure 3).

The right hepatic duct was absent. The posterior and anterior sectorial ducts, consecutively inflowed in the opposite left hepatic duct in the following order: the right posterior sectorial duct inflowed first and then the right anterior sectorial duct .

Both sectorial ducts inflow was related to portal vein, as has been described below.

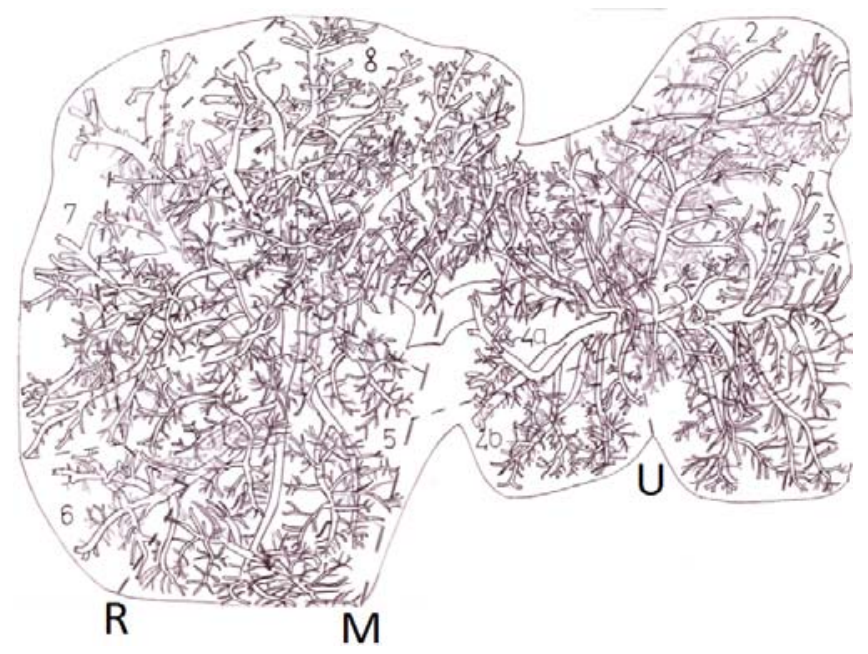

Figure 2: Intrahepatic branching of the portal vein. Portal segmentation outlining on the diafragmatic surface. The planes of the first to the third order division are marked: Main portal plane
(midplane)-M, Right portal intersectorial plane-R, Left portal intersectorial plane (umbilical)- $U$ and intersegmental planes.

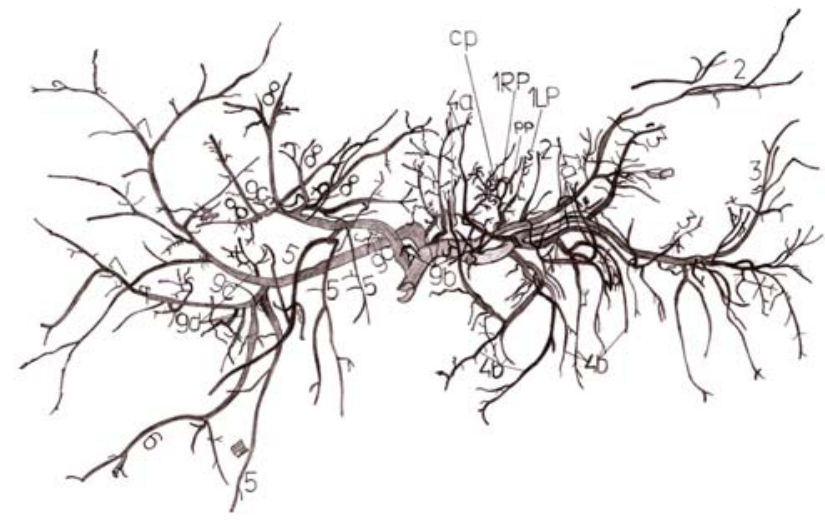

Figure 3: Merging pattern of intrahepatic biliary ducts for examined specimen: Segmental duct are numbered from 1 to 9, Left portion of caudate lobe (segment 1)-1LP, Right portion of caudate lobe (segment 1)-1RP, superficial-s, caudate process-cp and papillar process-pp.

\section{Right posterior sectorial duct-merging pattern}

In this case the $7^{\text {th }}$ segment duct with common stem of previously joined the double $7^{\text {th }}$ and $6^{\text {th }}$ segment ducts with one of several $5^{\text {th }}$ segment ducts confluenced into the right posterior sectorial duct (Figure 3).
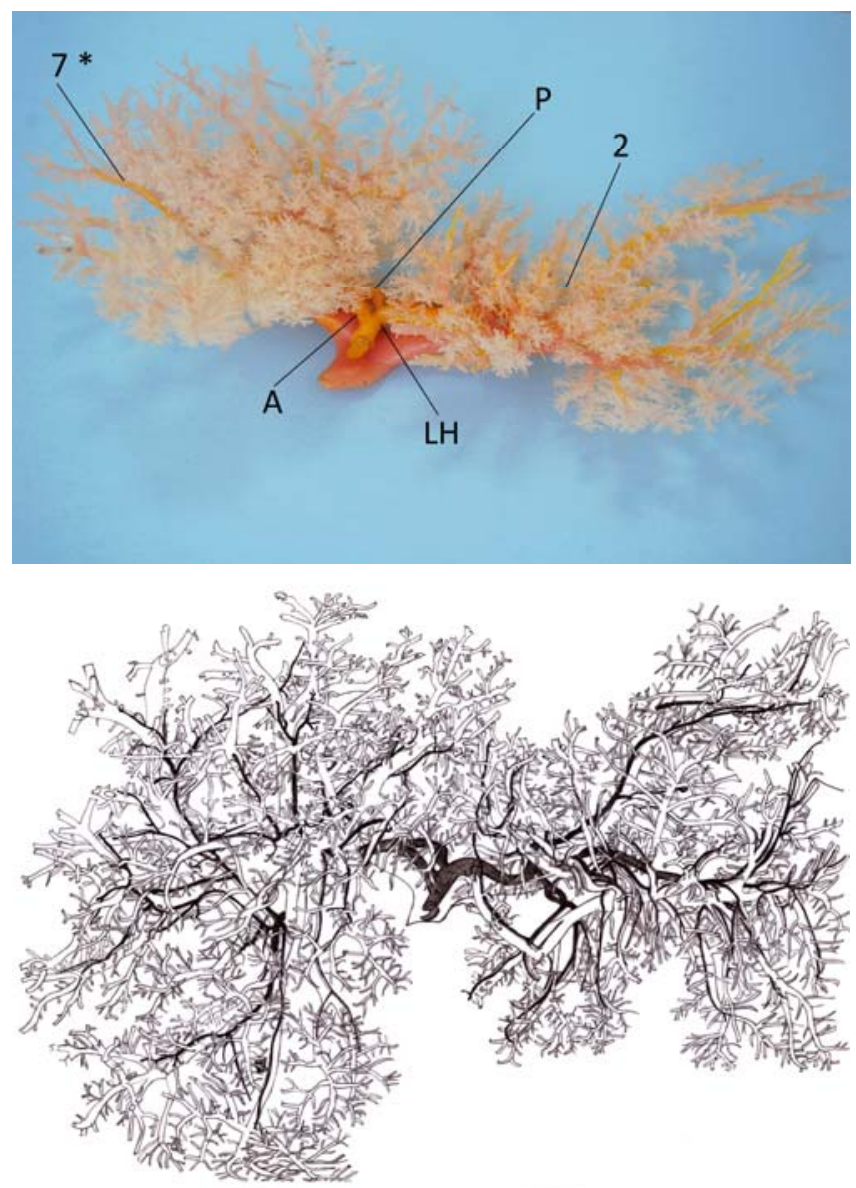

Figure 4: Diafragmatic view of injection-corrosive cast of liver portobiliary system. Right sectorial duct (posterior-P and anterior $-A$ ) 
and Left hepatic duct-LH in front of the portal bifurcation. Main duct of $2^{\text {nd }}$ segment -2 above and in front of the transverse part of left portal vein branch. Double $7^{\text {th }}$ segment ducts- $7^{*}$.

The site of junction was anteriorly and above to the initial part of $7^{\text {th }}$ segment portal branch (Figure 4).

The formed posterior sectorial duct then turned over the arch of anterior portal vein branch and continued at a distance anteriorly and above to the posterior margin of right portal vein branch. Just above and in front of the portal bifurcation this sectorial duct entered the left hepatic duct (Figures 4 and 5).
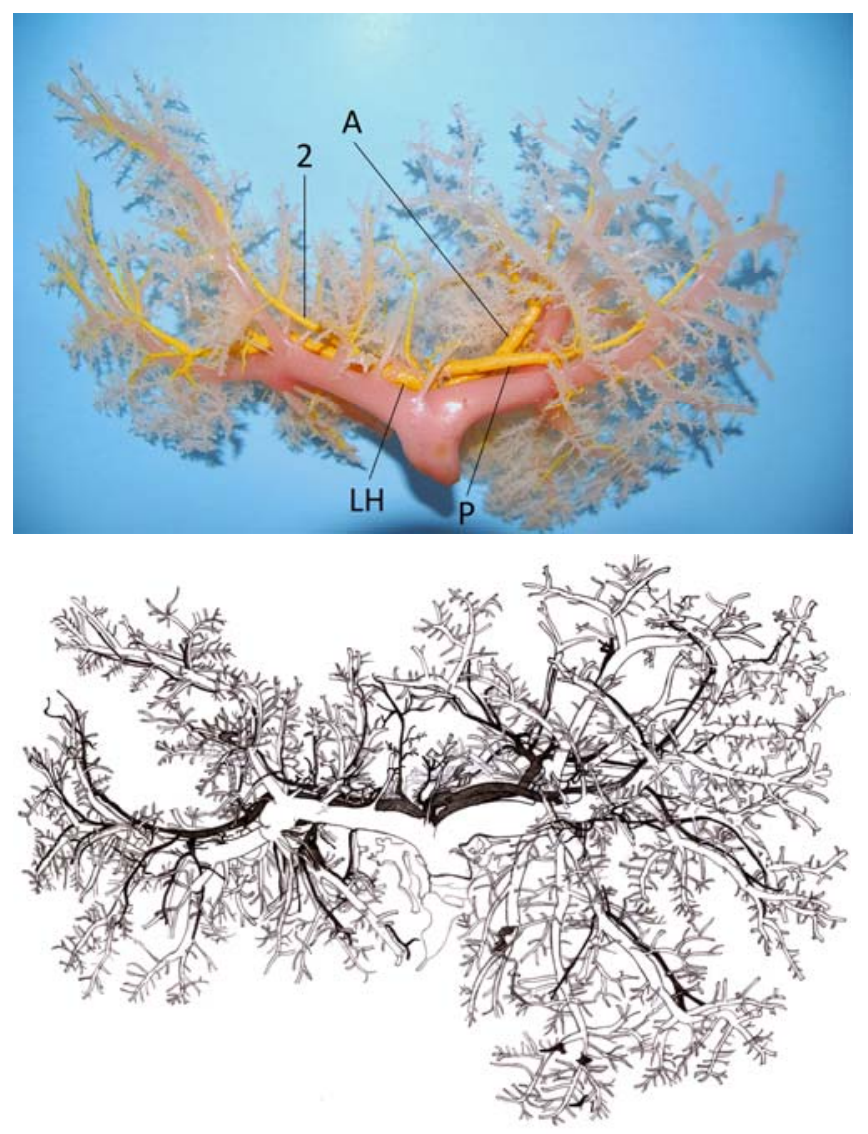

Figure 5: Visceral view of injection-corrosive cast of liver portobiliary system. Aberrant confluence of Right posterior sectorial duct$P$, Right anterior sectorial duct- $A$ and $2^{\text {nd }}$ segment duct-2 into the Left hepatic duct-LH.

\section{Right anterior sectorial duct-merging pattern}

In this case two $8^{\text {th }}$ segment ducts confluenced into the right anterior sectorial duct.

The site of junction was on the posterior surface of initial part of the terminal left branch of anterior portal vein branch (Figure 5).

The formed anterior sectorial duct continued arch-like to the right at a distance to the left side of the anterior portal vein branch and then descended anteriorly to the right portal vein branch until the portal bifurcation.
At this level, anteriorly and inferiorly to the right posterior sectorial duct it joined the left hepatic (Figure 4).

Up to the constituent ducts for the above mentioned sectorial ducts there were additional ones i.e. accessory tributaries (Figure 3).

\section{Left lateral sectorial duct-merging pattern}

Despite the convetional confluent model $(3+2)$ there was aberrant one. The main $3^{\text {rd }}$ segment duct joined the double medial sectorial duct forming left lateral sectorial duct. The site of junction was on the anterior surface of the terminal part of transverse part of left portal vein branch (Figure 4). The formed left lateral sectorial duct ran on the lateral third of above mentioned branch. At this level it confluenced the main medial sectorial duct.

So, the left lateral sectorial duct was a short, arch-like duct at the anterior surface of lateral third of transverse part of left portal vein branch.

\section{Left medial sectorial duct-merging pattern}

According to the merging segmental ducts a total duplication of this duct was found.

The main medial sectorial duct had a conventional inflow of both, the $4 \mathrm{a}$ and $4 \mathrm{~b}$ segments as follows: common stem of the $4 \mathrm{a}$ and $4 \mathrm{~b}$ segment ducts with $4 \mathrm{~b}$ segment duct. This inflow i.e. the site of junction was right to the umbilical part of left portal vein branch and above to the beginning part of main portal branch to $4 a+4 b$ segments originating from right horn of Rex`s recess.

The formed duct ran to the right and posteriorly until the middle of anterior surface of lateral third of transverse part of left portal vein branch where it joined the left lateral sectorial duct (Figures 3 and 4).

The double medial sectorial duct had an uncommon inflow of segmental ducts as follows: a common stem (i.e. trifurcation) of $4 \mathrm{a}$ segment duct, stem of $4 \mathrm{a}$ and $4 \mathrm{~b}$ segment ducts and $4 \mathrm{a}$ segment duct joined the triple $3^{\text {rd }}$ segment duct. The site of junction was at the middle of anterior surface of umbilical part of left portal vein branch. The formed duct ran from it to the terminal part of transverse part of left portal vein branch.

At this level it joined the main $3^{\text {rd }}$ segment duct (Figure 4). Up to the constituent ducts for the main and double medial sectorial ducts there were accessory segmental ducts with collateral inflow (Figure 3).

As to the $2^{\text {nd }}$ segment there were one main and two accessory segmental ducts with collateral inflow in the main $2^{\text {nd }}$ segment duct. The main duct of $2^{\text {nd }}$ segment had a sinuous flow along the main portal branch for this segment. From there on the duct passed behind the accessory portal branches for $2^{\text {nd }}$ 
segment and then was placed above and in front of transverse part of left portal vein branch to end into the left hepatic duct.

The site of junction was anteriorly and above the posterior margin of transverse part of left portal vein branch between middle and medial third of its length (Figures 4 and 5).

The left hepatic duct had a conventional confluent pattern i.e. the left lateral sectorial duct joined the main left medial sectorial duct. The site of junction was at the middle of anterior surface of lateral third of the transverse part of left portal vein branch. This duct had a sinuous flow in front of the above mentioned portal branch until the middle of portal bifurcation. From this level it continued as a common hepatic duct. Thus, this level was the upper biliary confluence (Figure 4).

In this case the $\mathbf{1}^{\text {st }}$ segment duct (so called caudate lobe or Left Dorsal Sector-LDS) had a collateral inflow of unique duct into the main $2^{\text {nd }}$ segment duct (Figure 5).

As a part of neighboring segments there was a $9^{\text {th }}$ segment (so called Right Dorsal Sector-RDS with 3 constituent subsegment b, $c$ and d). There was different collateral inflow for subsegment $c$ and $d$ only into right segmental or sectorial ducts, whereas for subsegment $b$ into right sectorial ducts, the main $2^{\text {nd }}$ segment duct and left hepatic duct.

Despite of the followed segmental ducts there weren 't first ductules, except for few number of ducts which drainaged the $4 a, 4 b$ and $5^{\text {th }}$ segments and RDS $b$ and $d$ subsegments.

So, the segmental ducts were observed as shorter than the accompanied portal branches except the minority of them which were longer than the accompanied portal branches (main $3^{\text {rd }}$ segment duct, one of $4 \mathrm{~b}$ and two of $4 \mathrm{a}$ segments, caudate process duct and one of RDS $b$ ducts).

\section{Discussion}

The presented aberrant confluence of both, the right posterior and anterior sectorial ducts into the opposite left hepatic duct corresponded to Couinaud`s[1] type "f", respectively to Ohkubo's [4] and to Huang's [3, 5-7] type "C". Exactly, in this case the two right sectorial ducts were very close to each other and we had found three ducts (right posterior and anterior sectorial ducts and left hepatic duct in front of the portal bifurcation).

According to determined midplane of division which passed anteriorly to the portal bifurcation and right to the parenchyma of caudate lobe and $9 \mathrm{~b}$ subsegment transversally in direction to Cantlie's line the three ducts were found. As to the clinical implication of such cases of aberrant confluence in Living Donor Liver Transplantation-LDLT [4-6, 8, 9-14] and new techniques of biliary reconstruction with or without ductoplasty $[7,15]$ it was possible to harvest them to right or to left hemihepatectomy [16]. The literature data revealed that there was an increasing risk for biliary complications in LDLT when multiple anastomoses had to be performed [17].

The incidence of biliary complication for segmental grafts and in partial liver transplantation was more common than in living donor or cadavericfull-size liver transplantation [3, 7]. In contribution to this statement was the following of additional segmental ducts and their aberrant confluence as a complete or partial scission and sliding to other ducts than the sectorial one. Their applied existence was caused not only by merging pattern, but by topographic disposition.

In presented case the site of junction of triple $3^{\text {rd }}$ duct, $4 \mathrm{a}$ and $4 \mathrm{~b}$ segment ducts into total duplication of medial sectorial duct on the middle of anterior surface of umbilical part of left portal vein branch was found. Also, the $2^{\text {nd }}$ segment ducts in relation to the transverse part of left portal vein branch, were seen. We think that such topographic disposition of left hemiliver segmental ducts was of relevant importance to LDLT in operative, as well as in postoperative period.

As preferred Miller et al. [17] left lateral segment grafts (segment 2 and 3) were used from adults for transplantation into children or for adult left lobe recipients on the contrary to right lobe donors. In accordance with Couinaud's [1] look on resection of segment 7 on presented specimen, a separate unique pedicle for both segments 7 and 6 i.e. trifurcation of right portal vein was seen.

Also, only the dorsal portal vessels (RDS d) were united with segment 7 . But below the segment 7 pedicle there was a double $7^{\text {th }}$ segment duct accompanying the collateral branch of $7^{\text {th }}$ segment portal branch. The sliding of $5^{\text {th }}$ segment duct into a short common stem of double $7^{\text {th }}$ and $6^{\text {th }}$ segment ducts was followed.

Are they the limiting biliary anatomy for reduced resection of segment 7 such as a partial superior segmentectomy, probablly is clinical implication.

As to the absence of first ductules, it is important for clinical practice for two reasons: the first as a sign of fibro-obliterative deseases [18-26] and the second considering minimum detectable duct caliber in imaging radiologic researches [27-29]. From LDLT point of view it is important in evaluation of age and functional-size-mass related liver parenchyma changes for donors and recipients.

Conclusion: The investigation and the finding out in anatomy of biliary ducts, emphasized the importance of the knowledge of both basic morphology and aberrant portobiliary anatomy. In clinical practice, the aberrant confluence of biliary 
ducts that was described and commented in this specimen, was found to be relevant from aspect of liver surgery, both in resections and in transplantations. Not just for cases that required more complex biliary reconstruction, but also in cases were the aberrant biliary anatomy might influence an unexpected limited resection.

\section{References}

1. Couinaud C. Tell me more about liver anatomy. Paris: Karger, 1999:IX, 6, 72.

2. Couinaud C. Surgical anatomy of the liver revisited. Pers. Ed. Paris; 15, rue Spontini, F 75116, 1989:p. 112.

3. Huang TL, Cheng YF, Chen $C L$ et al. Variants of the bile ducts: clinical application in the potential donor of living-related hepatic transplantation. In: Kim DR, Sakamoto S, Haider AM et al. Role of magnetic resonance cholangiography in assessing biliary anatomy in right lobe living donors. Transplantation. 2005; 79 (10):1417-21.

4. Ohkubo M, Nagino $M$, Kamiya J et al. Surgical anatomy of the bile ducts at the hepatic hilum as applied to living donor liver transplantation. Ann Surg. 2004;239 (1):82-6.

5. Kim DR, Sakamoto S, Haider AM et al. Role of magnetic resonance cholangiography in assessing biliary anatomy in right lobe living donors. Transplantation. 2005;79(10):1417-21.

6. Limanond P, Raman SS, Ghobrial RM, Busuttil WR, Lu SKD The utility of MRCP in preoperative mapping of biliary anatomy in adult-to-adult living related liver transplant donors. J Magn Reson Imaging. 2004; 19:209-15.

7. Feng NX, Ding FC, Xing YM, Cai XM, Zheng SS. Technical aspects of biliary reconstruction in adult donor liver transplantation. Hepatobiliary Pancreat Dis Int. 2011; 10 (2):136-42

8. Ayuso RJ, Ayuso C, Bombuy E et al. Preoperative evaluation of biliary anatomy in adult live liver donors with volumetric mangafodipir trisodium enhanced magnetic resonance cholangiography. Liver Transpl. 2004; 10 (11):1391-7.

9. Testa G, Malago M, Gamazo VC, Lindell G, Broelsch ECh Biliary anastomosis in living related liver transplantation using the right liver lobe: techniques and complications. Liver Traspl. 2000; 6 (6):710-4.

10. Bak T, Wachs M, Trotter J et al. Adult-to-adult living donor liver transplantation using right-lobe grafts: results and lessons learned from a single center experience. Liver Transpl. 2001; 7 (8):680-6.

11. Schroeder T, Malago M, Debatin FJ, Testa G, Nadalin S, Broelsch ECh, Ruehm GS. Multidetector computed tomographic cholangiography in the evaluation of potential living liver donors. Transplantation. 2002; 73 (12):1972-4.

12. Liu LCh, Lo MCh, Chan ChS, Tso KW, Fan TSh. The right may not be always right: biliary anatomy contraindicated right lobe live donor liver transplantation. Fujisawa Healthcare, Inc. Presents Images in Liver Transplantation. Liver Transpl. 2004; (6):811-2.

13. Lee SV, Krinsky AG, Nazzaro AC et al. Defining intrahepatic biliary anatomy in living liver transplant donor candidates at mangafodipir trisodium-enhanced MR cholangiography versus conventional T2-weighted MR cholangiography. Gastrointestinal Imaging. Radiology. 2004; 233:659-66.

14. Lim SJ, Kim MJ, Kim HJ et al. Preoperative MRI of potential living-donor-related liver transplantation using a single dose of gadobenate dimeglumine. Hepatobiliary Imaging. AJR 2005; 185:424-31.
15. Kim HS, Lee WK, Kim KY et al. Tailored Telescopic Reconstruction of the Bile Duct in Living Donor Liver Transplantation. Liver Transpl. 2010; 16:1069-74.

16. Broelsch CE, Malagó M, Testa G, Valentin Gamazo C. Living donor liver transplantation in adults: outcome in Europe. Liver Transpl. 2000;6(6 Suppl 2):S64-5.

17. Miller MCh, Gondolesi EG, Florman S et al. One hundred nine living donor liver transplants in adults and children: a singlecenter experience. Ann Surg. 2001; 234 (3):301-12.

18. Lee MY, Kaplan MM. Primary sclerosing cholangitis. Medical Progress. N Engl J Med. 1995; 332(14):924-33.

19. Ito K, Mitchell GD, Outwater KE, Blasbalg R. Primary Sclerosing Cholangitis: MR Imaging Features. AJR. 1999;172(6):1527-33.

20. Revelon G, Rashid A, Kawamoto S, Bluemke AD. Primary Sclerosing Cholangitis:MR Imaging Findings with Pathologic Correlation. AJR. 1999; 173:1037-42.

21. Dodd III DG, Baron LR, Oliver III HJ, Federle PM. End-Stage Primary Sclerosing Cholangitis: CT Findings of Hepatic Morphology in 36 Patients. Gastrointestinal Imaging. Radiology. 1999; 211: 357-62.

22. Angulo P, Lindor DK. Primary Sclerosing Cholangitis. Clinical Challenge. Hepatology. 1999;30(1) 325-32

23. Vitellas MK, Keogan TM, Freed SK, et al. Radiologic Manifestation of Sclerosing Cholangitis with Emphasis on MR Cholangiopancreatography. Scientific Exhibit. Radio Graphics. 2000; 20:959-75

24. Bader RT, Beavers LK, Semelka CR. MR Imaging Features of Primary Sclerosing Cholangitis: Patterns of Cirrhosis in Relationship to Clinical Severity of Disease. Radiology. 2003; 226: $675-85$

25. Sawai H, Matsubayashi $H$, Sasaki $K$ et al. A Case of Sclerosing Cholangitis without Pancreatic Involvement Thought to be Associated with Autoimmunity. Case Report. Intern Med. 2011; 50:433-8.

26. Kochar R, Nevah IM, Lukens JF, Fallon BM, Machicao IV. Vanishing bile duct syndrome in human immunodeficiency virus: Nevirapine hepatotoxicity revisited. Case Report. World J Gastroenterol. 2010; 16(26):3335-8.

27. Wallner KB, Schumacher AK, Weidenmaier W, Friedrich MJ. Dilated Biliary Tract: Evaluation with MR Chilangiography with a T2-weighted Contrast-enhanced Sequence. Radiology. $1991 ; 181: 805-8$

28. Fulcher SA, Turner AM, Capps WG, Zfass MA, Baker MK. Half-fourier rare MR cholangiopancreatography: experience in 300 subjects. Gastrointestinal Imaging. Radiology. 1998; 207:21-32.

29. Fulcher SA, Turner AM, Franklin JK, et al. Primary Sclerosing Cholangitis: Evaluation with MR Cholangiography- A CaseControl Study. Gastrointestinal Imaging. Radiology. 2000; 215: 71-80. 